\title{
MODCOMP MAX IV SYSTEM PROCESSORS REFERENCE GUIDE
}

\author{
by \\ J. CUMMINGS
}

Prepared under

Contract No. DE-AC03-89ER51114 for the U.S. Department of Energy

GENERAL ATOMICS PROJECT 3466 DATE PUBLISHED: OCTOBER 1990

GENERAL ATOMICS MASTER 


\title{
MODCOMP MAX IV SYSTEM PROCESSORS
}

\author{
USERS REFERENCE GUIDE
}

Author: John W. Cummings

Abstract

A user almost always faces a blg problem when having to learn to use a new computer system. The information necessary to use the system is often scattered throughout many different manuals. The user also faces the problem of extracting the information really needed from each manual. Very few computer vendors supply a single 'Users Gulde or even a manual to help the new user locate the necessary manuals. Modcomp is no exception to this. Modcomp MAX IV requires that the user be famillar with the system file usage which adds to the problem. At General Atomics there Is an ever Increasing need for new users to learn how to use the Modcomp computers. This paper was written to provide a condensed 'Users Reference Gulde' for Modcomp computer users. This manual should be of value not only to new users but any users that are not Modcomp computer systems experts.

This 'Users Reference Gulde' Is Intended to provided the basic Information for the use of the various Modcomp System Processors necessary to, create, compile, link-edit, and catalog a program. Only the Information necessary to provide the user with a basic understanding of the Systems Processors is included. This document provides enough information for the majority of programmers to use the Modcomp computers without having to refer to any other manuals. A lot of emphasis has been placed on the flle description and usage for each of the System Processors. This allows the user to understand how Modcomp MAX IV does things rather than just learning the system commands.

\section{Introduction}

This manual consists of many parts describing the various System Processors. A detailed description of each System Processor is provided in the appropriate Modcomp Manual, which will be listed after each section. This document consists of the following parts:

- File Description and Use - Describes the files used by the System Processors and how they are used

- Job Control

- Job Control Sequence link-edit, and

- Source Editor

- Compiler Processor

- Assembler

- Link-Editor

- Cataloger Processor

- Multiuser System Job Control
- Command Line Interpreter

- This part describes the overall procedure to, create, compile, catalog a program.

- Describes "ie use of the Source Editor (SED) System Processor

- Describes the use of the Ratfor and FORTRAN compiler System

- Describes the use of the Assembler System Processor

- Describes the use of the LInk-Editor System Processor

- Describes the use of the Task Overlay Cataloger System

- Describes the Neutral Beam Multiuser system and some of the Procedures available. 


\section{Elle Description and Use}

Job control and the System Processors use several different files for the input and output operations performed by each. The files are logical names and are not necessarily disk files. Some of the flles may be thought of as data streams rasher than particular devices. Others are typically logical disk flle names. The important thing to remember is that the files are logical file names. The following is a description of the basic flle names used:

- SI - Source Input flle. This is actually an input source data stream that may be assigned to any device to Input source data from. It Is used by the System Processors that use source data as input.

- SO - Source Qutput flle. This is actually an output source data stream that may be assigned to any device to output source data to. It is used by the System Processors that output source data.

- BI - B Inary Input file. This is actually an Input binary data stream that may be assigned to any device to Input binary data from. It is used by the System Processors that use binary data as inpur.

- BO - Blnary Qutput flle. This is actually an output binary data stream that may be assigned to any device to output binary data to. It is used by the System Processors that output binary data.

- Cl - Command Input flle. This is the command input file stream that may be assigned to any device to Input Job Control commands or directives for the System Processors.

- CO - Computer to Qperator flle. This is the output file stream that may be assigned to any device used by Job Control and the System Processors, to output operator and error messages.

- LO - Listing Qutput file. This is the listing output file stream that may be assigned to any device, used by the Systems Processors for IIsting output data.

- SC - SCratch flle. This is the scratch flle that is used by some of the System Processors ( l.e. M4E ) for Intermediate file operations. It may be assigned to disk (typical) or to magnetic tape.

- USL - User Source Library flle. This is the logical file name that is assigned to the file that contains the users source data. It is typically assigned to a disk file, but could be assigned to a magnetic tape drive.

- JC - Job Control file. This is the logical file name that is assigned to the file that contains the global Job Control procedures. It is typically assigned to a disk file, but could be assigned elsewhere.

- UJC - User Job Control file. This is the logical flle name that is assigned to the file that contalns the user Job Control procedures. It is typically assigned to a disk flle, but could be assigned elsewhere.

- WRK - Random WoRK file. This is the logical flle name that is assigned to the random work disk flle used by the source editor. Must be a disk file.

- UL - User Library flle. This is the logical flle name that is assigned to the file that contains the users subroutine library in binary object code format. 
- TM - Iemporary Load Module file. This is the file that contains the users executable load modules. This is where the program is cataloged as a load module.

- NO - NO Is actually a null file. A logical file may be assigned to NO when no input or output is to be performed from/to the logical flle. I.E. ASS SI NO, ASS LO NO.

All logical flles have a current assignment and a default assignment. The current and default assignments are made when a user first signs onto the system. The assignments may be subsequently changed by executing the assign (ASS) or default (DEF) Job Control commands. The default (DEF) command does not change the current assignment until the set defaults (JOB) command is issued, or the logical file is assigned to itself. Each logical file also has a file position Index that is a pointer for the logical fille to the assigned device. The list of logical file current assignments, default assignments, and file-position Indices, for the Multiuser system at time of sign-on (SIgned on to Y "SYY", On BATO02) are as follows:

\begin{tabular}{|c|c|c|c|c|c|}
\hline $\begin{array}{l}\text { LOGICAL. } \\
\text { FILE } \\
\text { NAME }\end{array}$ & $\begin{array}{c}\text { CURRENT } \\
\text { DEVICE } \\
\text { ASSIGNMENT }\end{array}$ & $\begin{array}{l}\text { FILE } \\
\text { POSITION } \\
\text { INDEX }\end{array}$ & $\begin{array}{c}\text { DEFAULT } \\
\text { DEVICE } \\
\text { ASSIGNMENT }\end{array}$ & $\begin{array}{l}\text { CURRENT } \\
\text { FILE-TO-FILE } \\
\text { ASSIGNMENT }\end{array}$ & $\begin{array}{l}\text { DEFAILLT } \\
\text { FILE-TO-RILE } \\
\text { ASSIGNMENT }\end{array}$ \\
\hline SI & Al2 & 0 & $\overline{A l 2}$ & & \\
\hline So & $2 S B$ & 0 & 2SB & SCB & $\mathrm{SCB}$ \\
\hline BI & $2 S A$ & 0 & $2 S A$ & SCA & SCA \\
\hline $\mathrm{BO}$ & 2SA & 0 & $2 S A$ & SCA & SCA \\
\hline $\mathrm{Cl}$ & Al2 & 4 & $\mathrm{~A} / 2$ & & \\
\hline $\mathrm{CO}$ & A2 & 3 & A2 & & \\
\hline LO & A2 & 0 & 12 & & \\
\hline USL & YSL & 0 & YSL & & \\
\hline $\mathrm{JC}$ & $\overline{A J C}$ & 0 & $\overline{A J C}$ & & \\
\hline UJC & YSL & 0 & YSL & USL & USL \\
\hline WRK & YWK & 0 & $\overline{Y W K}$ & & \\
\hline UL & $\overline{Y L B}$ & 0 & YLB & & \\
\hline$T M$ & YTM & 0 & YTM & & \\
\hline
\end{tabular}
Control.

The commands to assign and manipulate filles are described in the following section on Job 


\section{Job control}

Job Control is Modcomp's command IIne interpreter. It provides the interface between the user and the system by allowing the user to Input commands that are interpreted by Job Control. The commands are Input from whatever device $\mathrm{Cl}$ is assigned to. Job Control commands can be written as sequence of commands that run as a Job Control Procedura. Global Job Control procedures are executed from the file that $\mathrm{JC}$ is assigned to. User Job Control procedures are executed from the flle that UJC Is assigned to. User Job Control procedures are normally executed before global procedures. Job Control uses $\$$ as the prompt character. It must be present ax the beginning of each Job Control directive. The following is a descriptlon of the logical flles used by Job Control, and some of the basic directives.

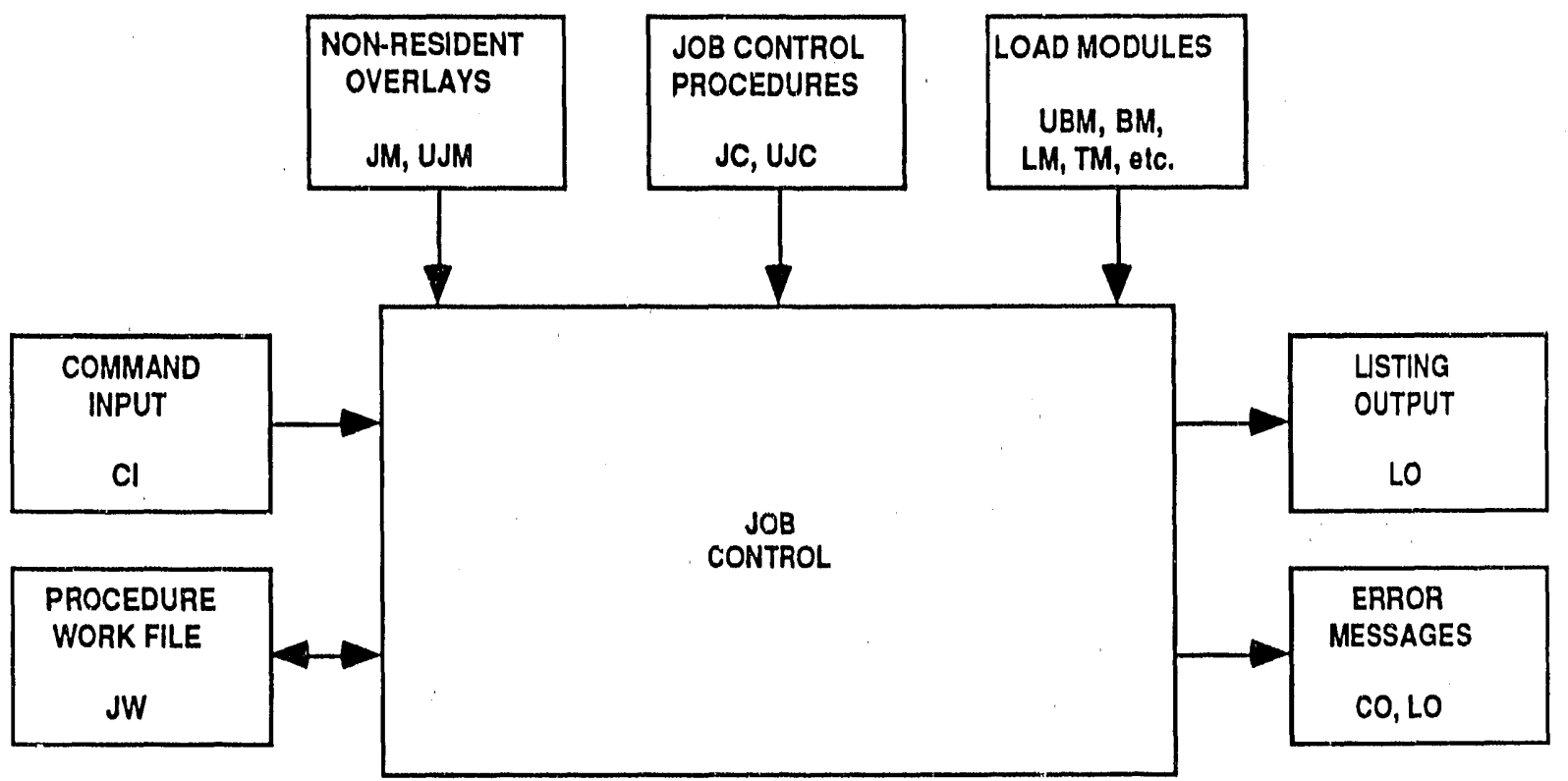

The principal logical flles used by Job Control are:

- Command Input $\quad$ - Job Control directlves are read from this logical file.

- Computer to Operator - Messages to the operator's attention are written to this file.

- Listing Output - Directlves are written to this file.

Other logical flles used by Job Control are:

- UJM, JM

- UJC, JC

- JW

- UBM
- These loglcal flles are used to siore custom-written Job Control directives.

- These logical illes are used to store Job Control procedures.

- This logical flle is used as a work area by Job Control when performing procedures.

- This logical flle, if it exists, is searched on the \$EXE commands prior to searching the the default logical flle. UBM is only searched if the logical file is defaulted and UBM exists. 
Some basic Job Control direstes are:

- \$ASSIgn - Changes cl rent assignment of a logical file name to a physical device name or another mogral flle.

I.E. SASS 5 - Changes current assignment of Source Input file to physical flle name YSL.

\$ASS IS ISL. Changes current assignment of Source Input flle to wherever logical file USL Is assigned.

- \$DEFault - Changes $r$ toult assignment of a logical flle name to a physical device name or anothe: 1 inlcal flle.

I.E. SDEF Y YSL - Changes default assignment of Source Input file to physical flle name YSL.

\$DE BO - Changes default assignment of Binary Input file to wherever logical file $\mathrm{BO}$ is assigned.

- \$REWind - Rewind the logical file to beginning of flle. Resets the Flle-Position-Index =0. I.E. \$F - Positlons the logical Binary Input file to beginning of the file that $\mathrm{BI}$ is assigned to.

- \$لB - Sets th assigntitists and rewinds all of the logical files (Flle-Position-Index $=0$ ). I.E. $\$ .0 \mathrm{~g}$

- \$WEQfile - Writes stind of flle (\$\$) to wherever the logical flle name is assigned. I.E. Is assigned.

- \$POSition - Posittorks to a modulename ( 1 to 8 bytes) that was cataloged by the Source Editch", wh disectorized fila on disk or magnetic tape.

I.E. - Positions logical file SI to modulename ABC on the directorized file that SI is assigned to. Note: You may specify some other logical file other than Si in optional parameter 2. SI is the default if parameter 2 is not specifled.

The above Job Controt inectives are the basic directlves that are commonly used. For a

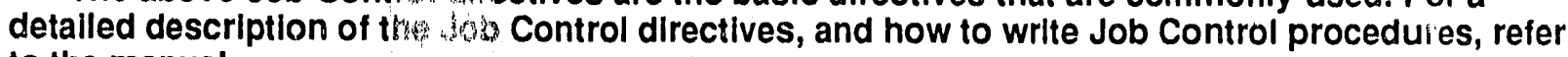
to the manual:

MAX IV/32 Programracer, Reference Manual, Nonresident Job Control and Batch Facllities

\section{Job Control Sequence}

The following is the ovinglin sequence of events to, create, compile, assemble, link-edit, and catalog a RATFOR (FORTFAM) program. 


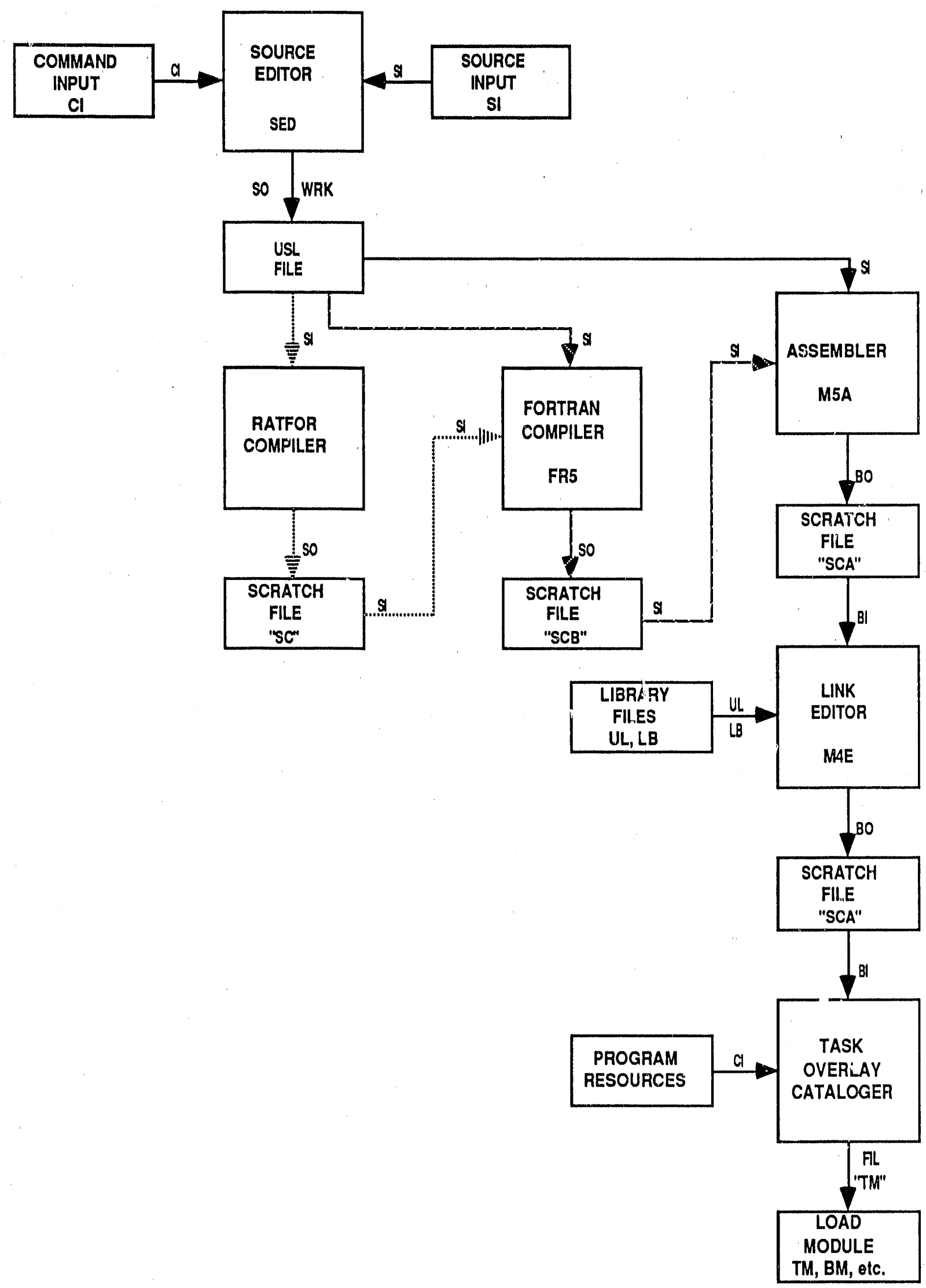


Command Sequence to, create or modify, complle, assemble, link-edit, and catalog a FORTRAN program

Create New Program "modulename" on USL

\$JOB

\$ASS USL "User's Source File, I.e. YSL" (Optlonal. May be done before or after entering

\$EXE SED

Source Editor ]

ASS USL "User's Source File, I.e. YSL" \{Optlonal. May be done before or after entering

OPT TWO,DAT

CLE ALL

SET TAB 8,25,36

NOQ

ASS SI NO

RAN

ADD 0

\{ Execute Source Editor \}

Source Editor \}

[Set Optlons for 2 line, and Date

\{ Clear old Tab settings \}

\{ Set Tab settings \}

\{ No Quick. Display source lines \}

\{ Assign Si to NO Input \}

[Set Source Editor to random mode \}

\{ Start adding source records at line 1 \}

$\star \star \star$

$\star \star \star$

$\star \star \star$

LIS

CAT "modulename"

EXI

\$JOB

\{Input: FORTRAN source records \}

\{ Terminate ADD mode. Period in column 1 terminates ADD \}

\{Optional. Lists source records to LO device \}

\{ Catalog source on USL file as 1 to 8 character "modulename" \}

\{ Exit the Source Editor \}

Modify an existing Program "modulename" on USL

\$JOB

\$ASS USL "User's Source Flle, I.e. YSL"

\$ASS SI USL

\$POS "modulename"

\$EXE SED

ASS USL "User's Source File, I.e. YSL"

ASS SI USL

POS "modulename"

OPT TWO,DAT

CLE ALL

SET TAB 8,25,36

NOQ

RAN

IOptional. May be done before or after entering Source Editor \}

\{ May be done before or after entering Source Editor \}

I May be done before or after entering Source

Editor )

\{Execute Source Ećitor \}

I Optlonal. May be done before or after entering Source Editor )

\{ May be done before or after entering Source Editor \}

I May be done before or after entering Source

Editor

\{ Set Options for 2 line, and Date \}

\{Clear old Tab settings \}

\{ Set Tab settings \}

\{ No Qulck. Display source lines \}

\{ Set Source Editor to random mode \}

Modify, Add, Delete, etc.

\{ Modlfy FORTRAN source records \}

LIS

\{Optional. LIsts source records to LO device \} 
Note: One of the following sequences of directlves must be done to catalog the new source on flle USL

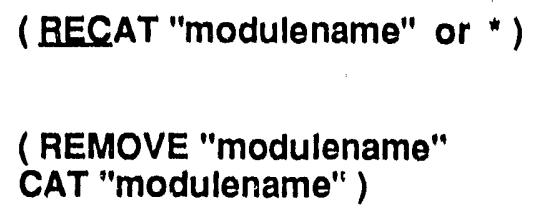

EXI

\$JOB
( ReCatalog source on USL flle as 1 to 8 character "modulename" \}

( Remove old FORTRAN source "modulename" from USL. Catalug new FORTRAN source "modulename" on USL)

\{ Note: Second method reduces file fragmentation \}

( Catalog new FORTRAN source as "new modulename" \}

\{ Exit the Source Editor\}

Complle FORTRAN program "modulename" on USL.

\$ASS USL "User's Source File, I.e. YSL" \$ASS SI USL. \$POS "modulename"

\$EXE FR5,,NOLO,NOMAP,NOSC,\$23

\$WEO SO

\{Optional. \}

\{Assign Source Input flle to USL \}

(Position Source Input fille (SI) to FORTRAN program \}

\{ Execute FORTRAN $V$ compller with the following options:

NOLO - No llsting output

NOMAP - No map output

NOSC - FORTRAN statements not output to So flle

$\$ 23$ - Set integer, logicals, and reals to single precision \}

\{Write end of flle (\$) to Source Output flle SO \}

Assemble output from FORTRAN compller (FR5) on Source Output flle SO

\$ASS SI SO

SREW SI

\$EXE M5A,NOLO,NOSC

\$WEO BO
[ Assign Source Input file SI to Source Output flle So \}

\{ Rewind Source Input file to beginning of file \}

( Execute M5A Assembler with the following optlons:

NOLO - No listing output

NOSC - Source records not copled scratch file SC ]

\{Write end of flle (\$\$) to Binary Output flle BO\} 
LInk-Edit program blnary object module from M5A to required modules on users llbrary flle UL

\$ASS BI BO

\$REW BI BO

\$EXE M4E,NOMAP

EDIT

WEO BO

EXI
( Assign Binary Input flle Bl to Binary Output file BO )

( Rewind BInary Input flle BI and BInary Output flle BO \}

[ Execute MAE LInk-Editor with NOMAP option ] \{ Perform link-edit \}

\{ Write end of flle ( $\$$ ) to Binary Output flle BO \} \{ Exit M4E LInk-Editor \}

Catalog binary object module from MAE as a load module on user load module file TM

\$ASS BI BO

\$REW BI BO

\$EXE TOC

FIL TM

\{ Assign Binary Input flle BI to Binary Output flle BO\}

( Rewind Binary Input flle Bl and BInary Output flle BO\}

\{ Execute Task Overlay Cataloger TOC \}

\{ Set load module flle to flle TM\}

Input: Task/Overlay name, Resources, and Options

CAT "program name"

\{See section on Task Overlay Cataloger TOC \}

( Catalog program as executable load module with name "program name"

EXI

\$JCB

[ Exit from Task Overlay Cataloger TOC ] 


\section{Source Editor (SED)}

The Source Editor (SED) is a MAX IV program that creates and maintains user source programs or text on files. SED has two modes of operation, Sequentlal and Random. Sequentlal mode modiflcations to the input source must be In sequence, that Is, records from the $\mathrm{SI}$ and $\mathrm{Cl}$ files are read in succession. At the same time that changes are being made to source records, the records are sequentlally written on the SO flle. Modiflcations to the input source, in Random mode, a. a not necessarlly in sequence. In this mode the source is held on the WRK flle (random work file), and the modiflcations are performed to the WRK flle. The user may specify random mode with the RANDOM directlve. The following is a description of the files used by SED and some of the basic SED directives:

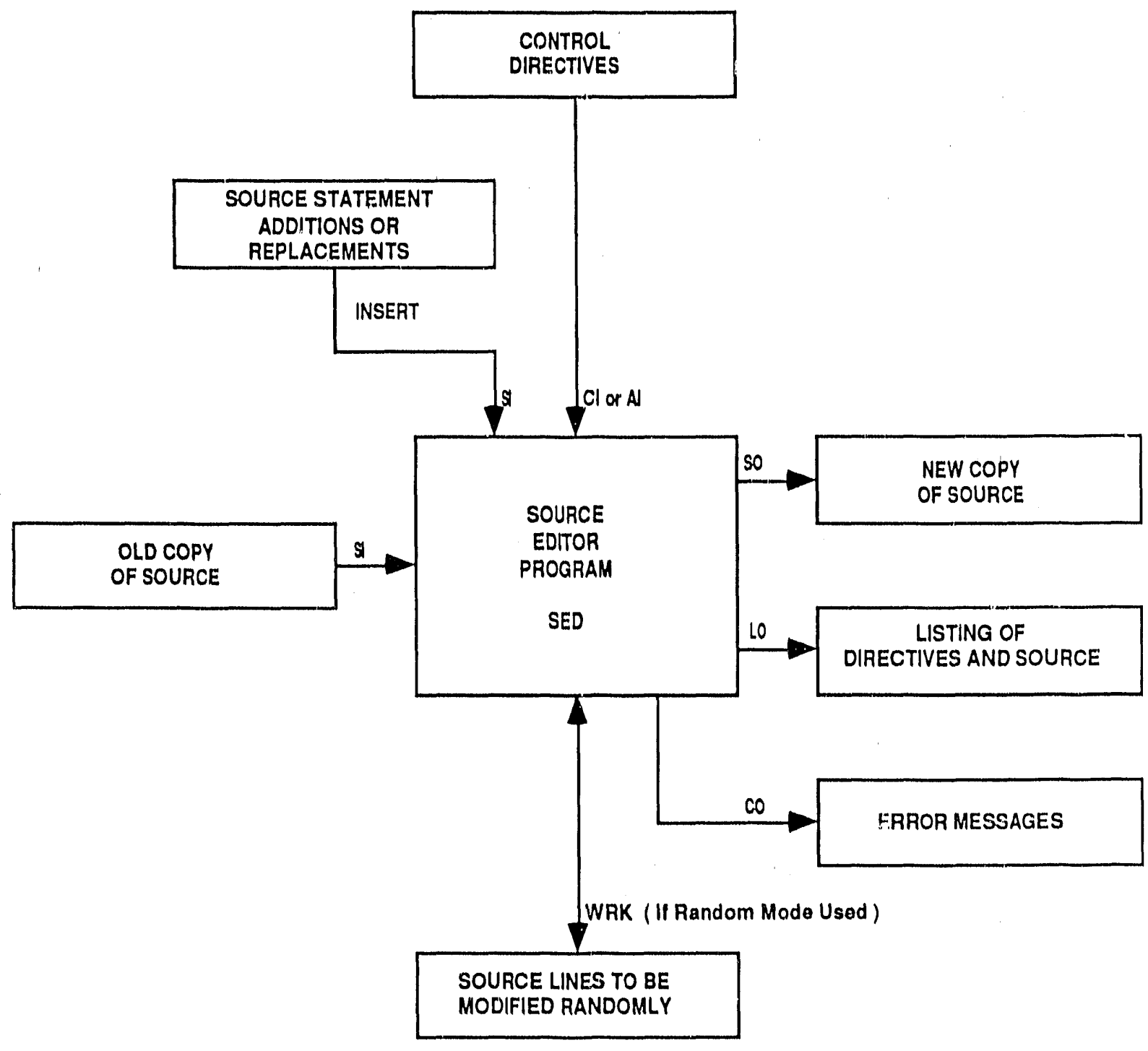


Resume of SED Directives

The following are the command categorles:

- Edit Instructions

- Listing of Source Files

- Edit Formatting and Control

- Directory Handling

- Flle Positioning

- Data Formatting

- Illscellaneus

The following is a description of the commonly used SED Directives. Note: The parameter SLR means Source Line Reference. 
Edit Instructions

\begin{tabular}{|c|c|c|}
\hline DIRECTIVE & DESCRIPTION & EXAMPLES \\
\hline ADD SLR & $\begin{array}{l}\text { Adds source recorols after SLR. If SLR is null, } \\
\text { then the current Ilne is taken by tefault. Source } \\
\text { records are added untII ADD is terininated by a } \\
\text { perio, in column } 1 \text {. }\end{array}$ & $\begin{array}{l}\text { ADD } 20 \\
\text { A }\end{array}$ \\
\hline DE' SLR-1 [ SLR-2] & $\begin{array}{l}\text { Deletes source records from SLR-1 to SLR-2. If } \\
\text { SLR-2 Is nuil then SLR-1 is deleted. If SLR-1 is } \\
\text { null then the current line is taken by default. } \\
\text { Note: C(urrent) imay be used for SLR-1 or SLR-2 } \\
\text { which uses the current line. }\end{array}$ & $\begin{array}{l}\text { DEL } 100200 \\
\text { DEL C,200 } \\
\text { DEL } 1, C \\
\text { DEL. }\end{array}$ \\
\hline BEP SLR-1 [SLF-2]. & $\begin{array}{l}\text { Replaces one or more source lines by one or } \\
\text { more additlonal line. Identical to a DELETE } \\
\text { followed by an ADD. }\end{array}$ & $\begin{array}{l}\text { REP } 100,200 \\
\text { REP } C, 300\end{array}$ \\
\hline CHA [(S1) (S2)] no nL & 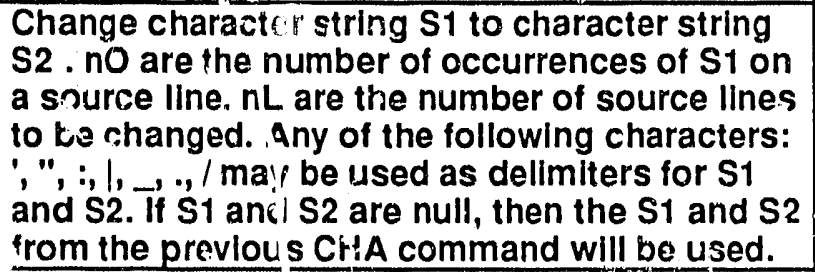 & $\begin{array}{l}\text { CHA } / A B C / X Y Z / 410 \\
\text { CHA :123:4567: } 3 \\
\text { CHA } \\
\text { CHA } 4100\end{array}$ \\
\hline UND & Undoes the last 1 ,hange made to the current line & $\bar{U}$ \\
\hline DUP SLR-1 [SLR-2] & $\begin{array}{l}\text { inserts the sourc e records from SLR-1 to SLR-2, } \\
\text { after the current Ine. If SLR-1 is null then the } \\
\text { current line is di iplicated. Current line pointer is } \\
\text { set to the last record Inserted. }\end{array}$ & $\begin{array}{l}\text { DUP } 25150 \\
\text { DUP } 37 \\
\text { DUP }\end{array}$ \\
\hline MOV SLR-1 [SLR-2] & $\begin{array}{l}\text { Inserts the source records from SLR-1 to SLR-2, } \\
\text { after the current line, and then deletes the } \\
\text { source records from SLR-1 to SLR-2. Current } \\
\text { line pointer is set to the last record inserted. }\end{array}$ & $\begin{array}{l}\text { MOV } 100110 \\
\text { MOV } 45\end{array}$ \\
\hline MOD SLR & $\begin{array}{l}\text { Modify the source record at SLR. If SLR is null, } \\
\text { then the current line is the default. The line to } \\
\text { be modifled is displayed on the CO file. The } \\
\text { user may now overlay characters, delete } \\
\text { characters, or insert characters. Deletion is } \\
\text { done by typing under the characters to be } \\
\text { deleted. Insertion is done by typing ^ before the } \\
\text { character where insertion is to start. A space } \\
\text { terminates insertlon. An \& is used to overlay } \\
\text { characters with spaces or to insert spaces. }\end{array}$ & $\begin{array}{l}\text { M 10 } \\
\text { ABCDE (old line) } \\
X_{-} \&^{A} Y Z \\
\text { XC YZE ( new line) }\end{array}$ \\
\hline
\end{tabular}




\begin{tabular}{|c|c|c|}
\hline DIRECTIVE & DESCRIPTION & EXAMPLES \\
\hline $\begin{array}{l}\text { GOTO [-] SLR } \\
\text { SLR (Integer value: }\end{array}$ & 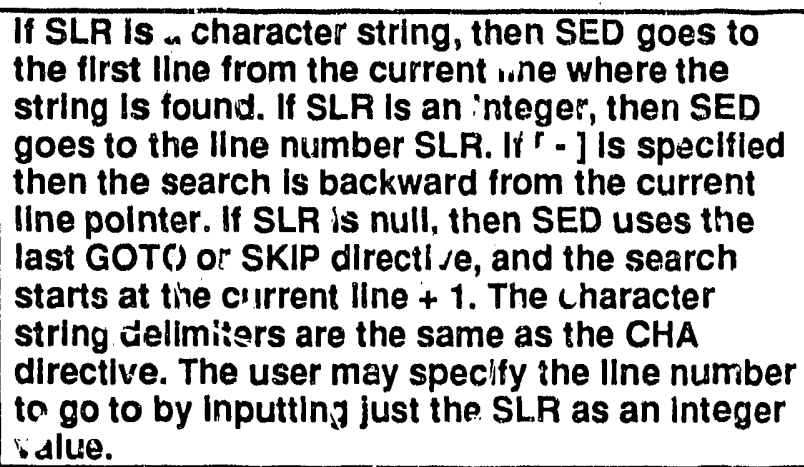 & $\begin{array}{l}\text { GOTO "ABCD" } \\
\text { GOT - IXYZI } \\
\text { G } 150 \\
120 \\
\text { G :HELLO: } \\
\text { G }\end{array}$ \\
\hline FOR [integer] & $\begin{array}{l}\text { SED moves the current line pointer forward } \\
\text { through the source module the specifled } \\
\text { number of lines. If the user does not specify a } \\
\text { parameter, then SED assumes a value of } 1 \text {. }\end{array}$ & $\begin{array}{l}\text { FOR 20 } \\
\text { F }\end{array}$ \\
\hline BAC. [integer] & $\begin{array}{l}\text { This directive is the same as FOR except the } \\
\text { current line pointer is moved backwards. }\end{array}$ & $\begin{array}{l}\text { BAC } 10 \\
\text { B }\end{array}$ \\
\hline
\end{tabular}




\begin{tabular}{|c|c|c|}
\hline DIRECTIVE & DESCRIPTION & EXAMPLES \\
\hline $\begin{array}{l}\text { LIS [Integer] } \\
\text { [ALL] }\end{array}$ & $\begin{array}{l}\text { LIS Is used to obtain a IIstling of source } \\
\text { programs on the LO flle. In sequential mode, } \\
\text { Integer is the number of programs to be llsted } \\
\text { from the SI file. If no parameter Is specifled, SED } \\
\text { will list one program. In random mode, Integer } \\
\text { specifles the number of lines to list from the } \\
\text { WRK flle. If no parameter Is specifled, SED will } \\
\text { IIst the whole program from the WRK flle. If the } \\
\text { ALL parameter is Speclfied, SED will list all of } \\
\text { the programs in the USL directory. }\end{array}$ & $\begin{array}{l}\text { LIST } \\
\text { LIS } \\
\text { LIS } 3 \\
\text { LIS ALL }\end{array}$ \\
\hline SEA (string) [integer] & $\begin{array}{l}\text { SEA causes SED to search for, and display on } \\
\text { the CO flle, } \\
\text { source IInes contalning a speciflc character } \\
\text { string specifled by the parameter string. Integer } \\
\text { specifies the number of lines to search from the } \\
\text { current line pointer. If Integer is not speclfled, } \\
\text { the entire module is searched. The current line } \\
\text { pointer is not affected by the SEA directlve. }\end{array}$ & $\begin{array}{l}\text { SEA /ABC/ } \\
\text { SEA :XYZ: } 100\end{array}$ \\
\hline PRI integer & $\begin{array}{l}\text { The PRINT directlve displays the specified } \\
\text { number of lines, beginning with the current line, } \\
\text { on the CO file. If no parameter is specifled, the } \\
\text { current line Is displayed. The current line pointer } \\
\text { is not affected by the PRI directive. }\end{array}$ & $\begin{array}{l}\text { PRI } 100 \\
P 10 \\
P\end{array}$ \\
\hline IEX & $\begin{array}{l}\text { The TEX directive causes SED to perform all } \\
\text { subsequent listings to the LO file in text format. } \\
\text { Line numbers, headings, and titles will not be } \\
\text { llsted. }\end{array}$ & $\begin{array}{l}\text { TEXT } \\
\text { TEX }\end{array}$ \\
\hline SQU & $\begin{array}{l}\text { The SOU directive causes SED to perform all } \\
\text { subsequent IIstings to the LO file In source } \\
\text { format. Line numbers, headings, and titles iwill } \\
\text { be l'sted. SOU is the default. }\end{array}$ & SOU \\
\hline LNA & $\begin{array}{l}\text { Causes SED to list only the source statements } \\
\text { containing special keywords such as } \\
\text { PROGRAM, TTL, etc. This directlve affects } \\
\text { subsequent LIST or COPY directives. }\end{array}$ & LNA \\
\hline LAL & $\begin{array}{l}\text { Causes SED to list all source statements when } \\
\text { subsequent LIST or COPY directives are } \\
\text { executed. LAL Is the default. }\end{array}$ & LAL \\
\hline
\end{tabular}


Edit Formatting and Control

\begin{tabular}{|c|c|c|}
\hline DIRECTIVE & DESCRIPTION & EXAMPLES \\
\hline QPI options & $\begin{array}{l}\text { This directive allows the user to set certain } \\
\text { options within SED. Some of the options are : } \\
\text { ONE - Each source record is displayed on one } \\
\text { line. Line numbers are not displayed } \\
\text { except for LIS. } \\
\text { TWO - Each source record is displayed on two } \\
\text { lines. Line numbers are always } \\
\text { displayed. } \\
\text { DAT - Saves date and time with a cataloged } \\
\text { program. } \\
\text { TAB - SED processes tabs when reading them } \\
\text { from a SI flle. } \\
\text { NOT - Treats tabs as normal ASCil chararters. } \\
\text { QUI - Quick mode. SED does not display } \\
\text { source lines accessed by the following } \\
\text { directives: GOTO,SKIP, CHA, FOR or } \\
\text { BAC. } \\
\text { NOQ - NoQuick mode. SED displays the } \\
\text { source lines accessed by the abcve } \\
\text { directives. }\end{array}$ & $\begin{array}{l}\text { OFT TWO,NOQ } \\
\text { OPT DAT }\end{array}$ \\
\hline $\begin{array}{l}\text { RAN [BECOVERY] } \\
\text { [EXIT] }\end{array}$ & $\begin{array}{l}\text { The RAN directive places SED In random mode. } \\
\text { SED coples the SI file to the WRK file. If } \\
\text { RECOVERY is SpEcifled, SED recovers the last } \\
\text { program placed on the WRK flle in random } \\
\text { mode. If EX!T is specifled, SED immediately } \\
\text { terminates random processing of the WRK file } \\
\text { and enters sequential mode. }\end{array}$ & $\begin{array}{l}\text { RAN } \\
\text { RAN RECOVERY } \\
\text { RAN REC } \\
\text { RAN EXIT } \\
\text { RAN EXI }\end{array}$ \\
\hline XRN & $\begin{array}{l}\text { Causes SED to terminate random processiritg of } \\
\text { the WRK flle ar.d enter sequential mode. }\end{array}$ & XRN \\
\hline INS file & $\begin{array}{l}\text { The INSERT directlve causes SED to read } \\
\text { source statement additions or replacements } \\
\text { from the specifled flle instead of from the CI file. } \\
\text { It allows a user to Insert source records from } \\
\text { another file, elther a scratch flle or from a } \\
\text { specified modulename on a USL flle. Executing } \\
\text { an ADD or REP directive after the INS directlve } \\
\text { will add the source records from the file } \\
\text { specifled in the "flle" parameter untll an EOF } \\
\text { (\$\$) Is encountered. Note: if flle SI is used, It } \\
\text { must be assigned back to its default after the } \\
\text { Insertlon, or subsequent ADD or REP directives } \\
\text { will cuntinue to read the source records from the } \\
\text { Inserted flle. }\end{array}$ & $\begin{array}{l}\text { ASS SI SCB } \\
\text { INS SI } \\
\text { ADD \{insert records } \\
\text { irom SCB file\} } \\
\text { ASS SI SI } \\
\text { ASS SI USL } \\
\text { POS "modulename" } \\
\text { INS SI } \\
\text { ADD finsert records } \\
\quad \text { from } \\
\text { "modulename\} } \\
\text { ASS SI SI }\end{array}$ \\
\hline
\end{tabular}




\begin{tabular}{|c|c|c|}
\hline DIRECTIVE & DESCRIPTION & EXAMPLES \\
\hline CAT name [ld] & $\begin{array}{l}\text { The CAT directlve causes SED to catalog a } \\
\text { specifled source module to the USL flle named } \\
\text { by the name parameter. The name parameter } \\
\text { may be any valid program name that does not } \\
\text { exceed } 8 \text { characters. In sequentlal mode, the } \\
\text { source module is copled from the SI flle. In } \\
\text { random mode, the source module is copled } \\
\text { from the WRK file, and SED then enters the } \\
\text { sequentlal mode. The optlonal parameter "ld" } \\
\text { may be used to record informaticn when the } \\
\text { program is saved. The "Id" parameter must be of } \\
\text { the same format as "name" and it will overide } \\
\text { the DATE and PGM optlons. }\end{array}$ & $\begin{array}{l}\text { CAT MYPROG } \\
\text { CAT ABC BIGONE }\end{array}$ \\
\hline BEC name [id] & $\begin{array}{l}\text { The REC directive is simllar to the CAT directlve, } \\
\text { except it allows the user to catalog a source } \\
\text { module with an existing name. IF the " parameter } \\
\text { is specifled, then the source module is } \\
\text { cataloged for the module located by the last } \\
\text { POSITION directlve. }\end{array}$ & $\begin{array}{l}\text { REC MYPROG } \\
\text { REC ABC BIGONE } \\
\text { REC * }\end{array}$ \\
\hline REM name & $\begin{array}{l}\text { The REMOVE dlrectlve deletes the specified } \\
\text { program "name"from the USL flle directory. }\end{array}$ & REM MYPROG \\
\hline REN name-1 name-2 & $\begin{array}{l}\text { The REN directive renames the program "name- } \\
1 \text { " to "name-2" on the USL flle directory. }\end{array}$ & $\begin{array}{l}\text { REN ABC XYZ } \\
\text { REN OLD,NEW }\end{array}$ \\
\hline LDI & $\begin{array}{l}\text { LDI causes SED to list the USL file directory to } \\
\text { the LO flle. }\end{array}$ & \\
\hline
\end{tabular}

File Positioning

\begin{tabular}{|l|l|l|}
\hline \multicolumn{1}{|c|}{ DIRECTIVE } & \multicolumn{1}{|c|}{ DESCRIPTION } & EXAMPLES \\
\hline POS name & $\begin{array}{l}\text { POS positions the SI file to the start of the } \\
\text { program specified by the name parameter, on } \\
\text { the USL flle. Note: Assign SI to the USL file } \\
\text { before executing the POS directlve. }\end{array}$ & POS ABC \\
\hline $\begin{array}{l}\text { AVF advances the flle pointer to the number of } \\
\text { flle markers specifled by the integer parameter. } \\
\text { If no Integer is specified, the file pointer is } \\
\text { advanced to the next flle mark. }\end{array}$ & $\begin{array}{l}\text { AVF SI 3 } \\
\text { AVF CI }\end{array}$ \\
\hline BKE file [integer] & $\begin{array}{l}\text { BKF is the same as AVF except it moves the file } \\
\text { pointer backwards. }\end{array}$ & BKF SI 2 \\
\hline REW file & $\begin{array}{l}\text { REW rewinds the file specifled in the file } \\
\text { parameter to the beginning of the file. }\end{array}$ & REW SI \\
\hline
\end{tabular}




\begin{tabular}{|c|c|c|}
\hline DIRECTIVE & DESCRIPTION & EXAMPLES \\
\hline $\begin{array}{l}\text { COP [integer] } \\
\text { [ALL] [NOR] } \\
\text { [USL] }\end{array}$ & 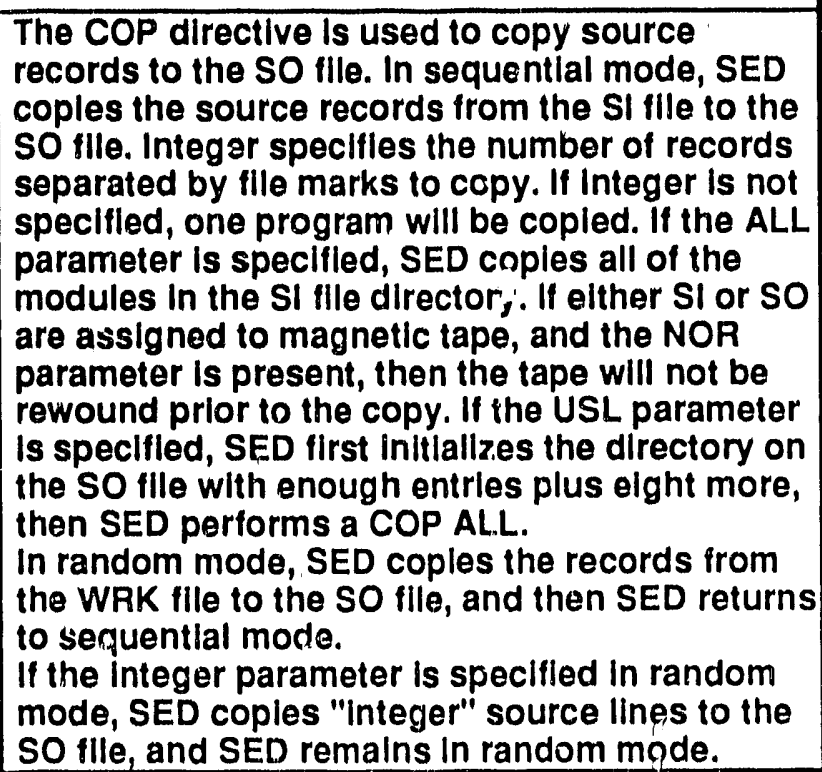 & $\begin{array}{l}\text { COP ALL NOR } \\
\text { COP ALL } \\
\text { COP USL } \\
\text { COP } \\
\text { COP } 6\end{array}$ \\
\hline
\end{tabular}

Miscellaneous Instructions

\begin{tabular}{|c|c|c|}
\hline DIRECTIVE & DESCRIPTION & EXAMPLES \\
\hline $\begin{array}{c}\text { MAC name [LIST] } \\
\text { [REMOVE] }\end{array}$ & $\begin{array}{l}\text { MAC defines a macro prototype. SED allows } \\
\text { users to define their own SED custom directlves } \\
\text { as a macro consisting of a sequence of regular } \\
\text { SED directives. When SED encounters the MAC } \\
\text { directlve, any subsequent SED directlve from } \\
\text { the Cl flle will be pur into the macro stack untll } \\
\text { an ENDM (end of macro ) directlve Is } \\
\text { encountered. SED will execute user defined } \\
\text { directlves first, allowing the user to replace a } \\
\text { standard SED directlve. The name of the macro } \\
\text { is specifled by the name parameter. If LIS is } \\
\text { specifled, SED Ilsts macro "name" on the CO } \\
\text { flle. If REM is specifled, SED removes the macro } \\
\text { "name" from the stack. } \\
\text { If no parameter are speclfled, SED ilsts all of the } \\
\text { currently deflined macros to the CO fllo. }\end{array}$ & $\begin{array}{l}\text { MAC X } \\
\text { OPT ONE } \\
\text { P } 20 \\
F 20 \\
\text { OPT TWO } \\
\text { ENDM }\end{array}$ \\
\hline ENDM & Ends the macro definition. & See Above \\
\hline EXIT & Exit from Source Editor SED. & EXi \\
\hline WEQ file & $\begin{array}{l}\text { WEO directive writes an end-of-file mark }(\$ \$) \text { to } \\
\text { the specifled flle. }\end{array}$ & WEO SO \\
\hline
\end{tabular}


The Source Editor SED has many more directlves than the ones described above. The above Ilst of directives should be sufficlent for most needs. For a more detalled description of the SED directlves, refer to the following manual:

\section{Programmer's Reference Manual MAX III/IV}

Source Editor

\section{Batfor and FOBTRAN Compllers}

This section describes the file usage of the compllers and some of the FORTRAN compller optlons. It is assumed that the user is famillar with the Ratfor and/or FORTRAN languages. If not, then the user should refer to the appropriate manuals.

\section{Ratfor Compiler}

The Ratfor compiler reads Ratfor source statements from the SI file, and converts them to equl'valent FORTRAN statements that are written to the the SO file. Complle errors are written to the LO flle. The Ratfor compller has no complle optlons.

\section{FORTRAN Compller}

There are two FORTRAN compllers, FR4 and FR5. The FR4 compller produces Modcomp IV assembly language Instructlons (M4A), and FR5 produces Modcomp V (Classic) assembly language instructions (M5A). We will use only the FR5 compller. The FORTRAN compiler reads FORTRAN statements from the SI flle, and translates them to equlvalent sequences of assembly language Instructions that are written to the SO flle. Complle errors are written to the LO file. Some of the common compiler optlons are:

LO - If the LO option is on, the compller IIsts the FORTRAN source and the dlagnostlc messages on the LO flle. The default Is LO.

NOLO - If the NOLO option Is on, the compller Ilsts only the dlagnostic messages to the LO file.

MAP - If the MAP option Is on, the compller lists the relevant symbol table information on the LO file for each program and subroutine complled. The default is MAP.

NOMAP - If the NOMAP optlon is on, the symbol table information will not be listed.

SC - If the SC option is on, the compller will write the FORTRAN statements as comments with the assembly language output to the SO file. The default is SC.

NOSC - If the NOSC option Is on, the FORTRA statements will not be written to the SO flle.

\$12 - If the \$12 option is on, all data explicitly or Implicitly typed INTEGER will be typed INTEGER*2.

\$L2. - If the \$L2 option is on, all data explicltly or Implicitly typed LOGICAL will be typed LOGICAL"2.

\$R6 - If the \$R6 option is on, all data expllcitly or Impllcitly typed REAL will be iyped REAL*6. 
\$R8 - If the \$R8 optlon Is on, all data explicitly or Implicltly typed REAL will be typed REAL"8.

\$D6 - If the \$D6 option Is on, all data explicitly or Implicitly typed DOUBLE PRECISION will be typed REAL*6.

$\$ 23$ - The $\$ 23$ option is equivalent to selecting the $\$ 12, \$ L 2$, and $\$ D 6$ simultaneously.

The FR5 compller is executed as follows:

\$EXE FR5, ,[ OPT1 ], [ OP'r2 ],[ OPTn ] Where: OPT1,OPT2,OPTn are the selected options

The following describes the flle usage for the Ratfor and FORTRAN compllers:

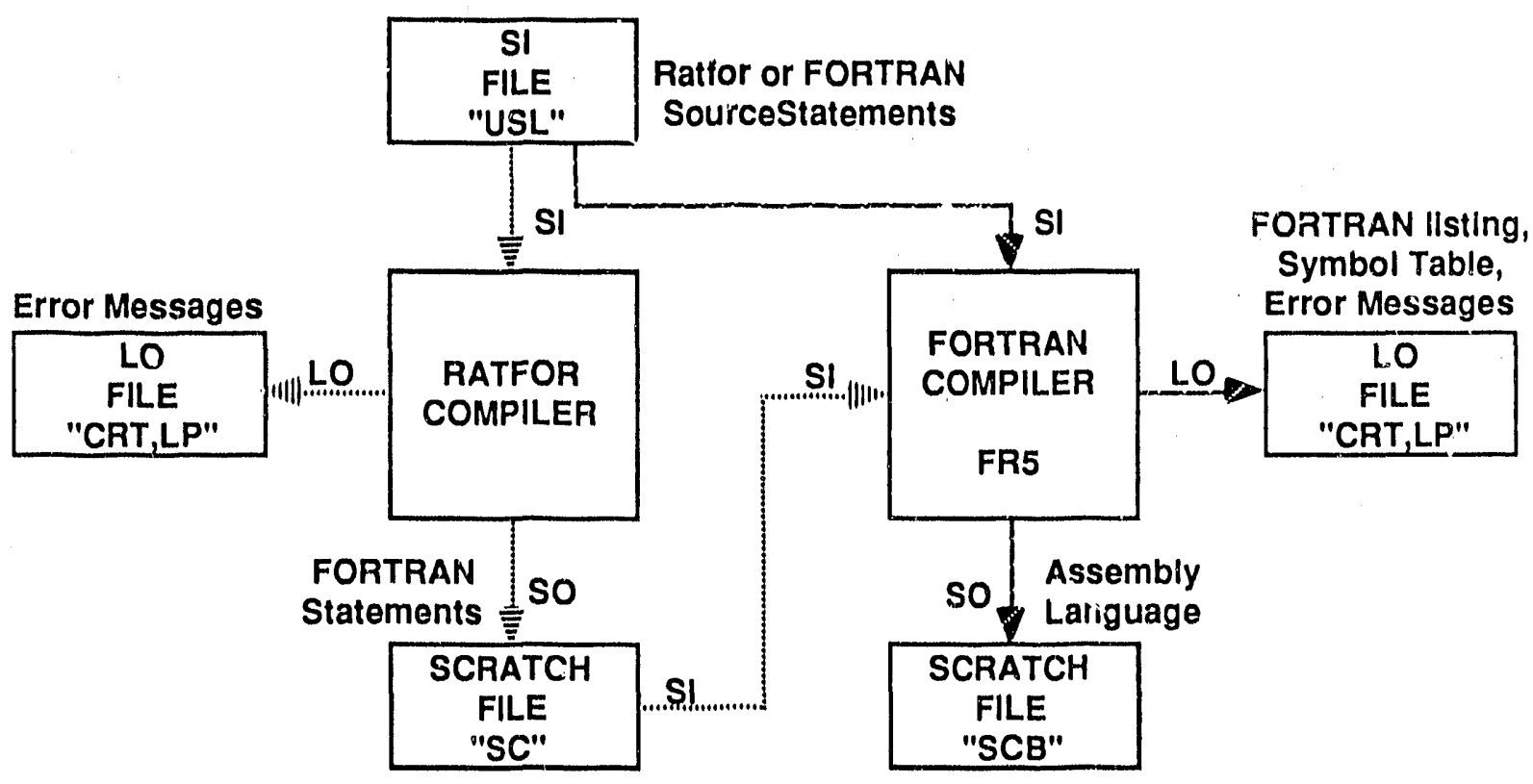

Refer to the following manuals for a detalled description of the compllers:

Ratfor Manual

Reference Manual MAX III/IV

FORTRAN 


\section{Assemblers}

There are two assemblers, M4A and M5A. M4A assembles statements in Modcomp IV assembly language. M5A assembles statements in Modcomp V ( Classic ) assembly language. We will conc arn ourselves only with the M5A assembler, though the M4A assembler is used for assembling the SYSGEN. The assembler reads assembly language source statements from the SI file, assembles them, and produces binary object code written to the Binary Output file BO. An optional assembly listing and error messages are written to the LO file. It Is assumed that the user is famillar with the Modcomp Assembly language, If not, then they should refer to the approprlate manuals. The following is a description of the assembler options and file usage.

Some of the common assembler options are:

BO - If option BO is on, object records will be written to the BO flle. The default is BO.

NOBO - :i option NOBO is on, object records will not be written to the BO file.

LO - If option LO is on, an assembly listing will be written to the LO flle. The default is 1.O.

NOLO - If option NOLO is on, an assembly listing will not be written to the LO file.

SC - If option SC is on, the source records are copled to the SC file on pass 1, and read from it on pass 2 . Generally used if the SI fille is assigned to a sequential access device. The default is SC.

NOSC - If option NOSC is on, the source records are not copied to the SC file. If the source records are from a random access device, the NOSC option should be used for reasons of efficiency.

\$PS - If option \$PS is on, the assembler symbol table will be listed on the LO file, each tIme an END card is encountered during pass 2.

\$PT - If option \$PT Is on, the assembler will list the information relating to symbol table size on the LO flle.

\$P1 - If option \$P1 is on, listed output will be produced on pass 1 as well as pass 2.

\$WK - If option \$WK Is on, the assembler will read the source records from the WRK file rather than the SI file. The WRK file must be In the Source Editor random mode format.

\$OP - If option \$OP is on, the assembler will perform instruction optimization.

The M5A assembler is executed as follows:

\$EXE M5A,[ OPT1 ], [ OPT2 ]:[ OPTn ] Where: OPT1,OPT2,OPTn are the selected options 
The following is a description of the flle usage by the assembler:

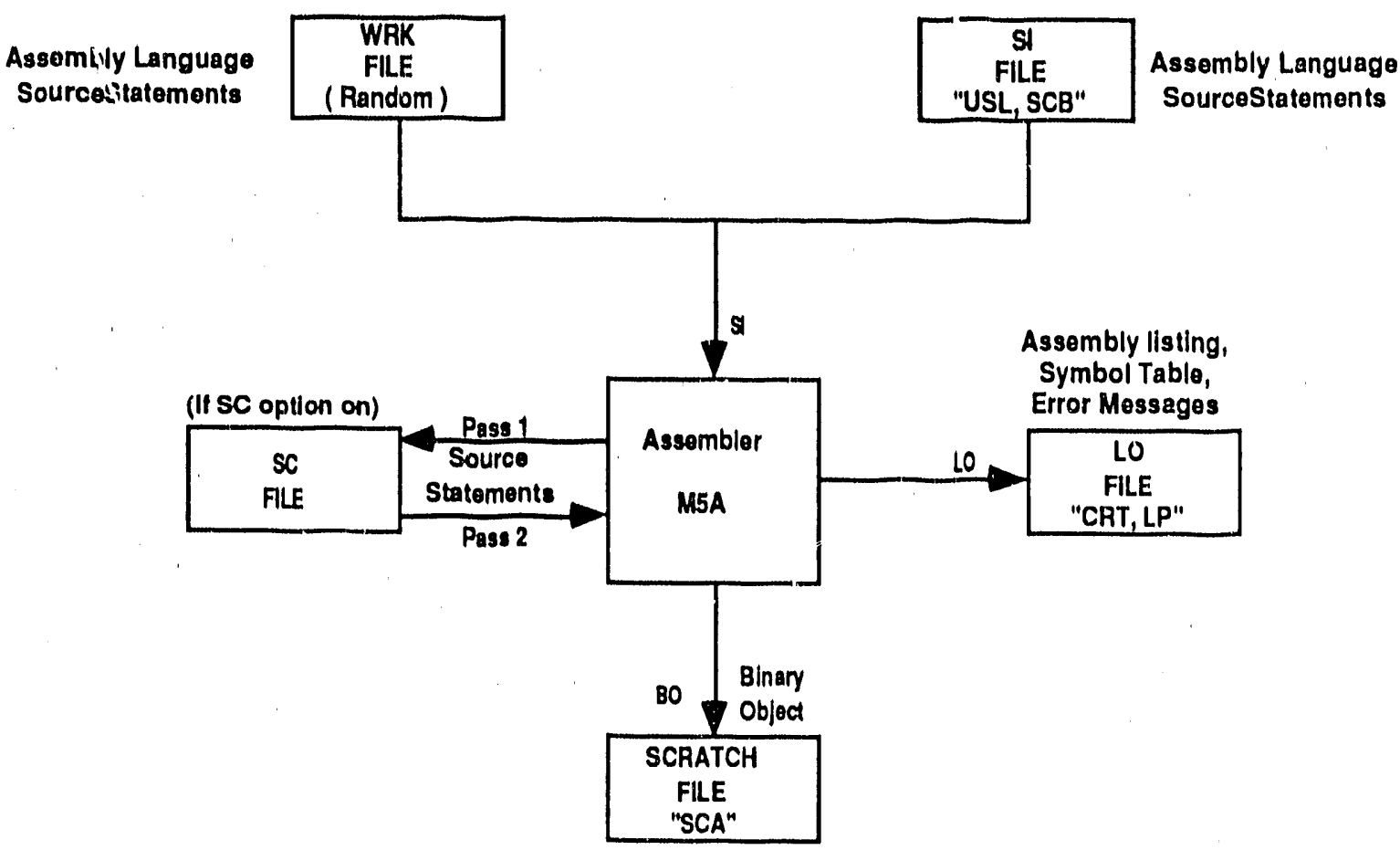

Refer to the following manuals for a detailed description of the Modcomp Assembly Language and assemblers:

\section{Reference Manual MAX III/IV \\ System Processors \\ Assemblers}

Reference Manual

Modcomp Classic

Central Processor 


\section{Link-Editor}

The MAX IV LInk Editor MAE links the main programs binary object module, produced by the assembler, to any referenced external binary object modules. The external blnary object modules may reside on Llbrary flles or have been assembled with the maln program. The object modules produced by the assembler are read by M4E from the BI flle. Any referenced external library object modules are read from the LIbrary Flles. The standard LIbrary flles are, the User Library flle (UL), and the System Library flle ( LB ). The M4E "LIBRARIES" directlve may be used to speclfy additional library flles to search, and the order In which they are searched. M4E is executed in two passes as follows:

Pass 1 - The primary object module is read and a coreuresident symbol table is constructed of all internal definitions, external references, and common allocation. All external references are then resolved from elther the speclfled input flle (BI.), the optlonal User Library flle (UL), the System I.Ibrary flle (LB), or from user specifled libraries. The valldity of all data is checked ciuring this pass.

If there are any unsatisfied external references, a search of the librarles is performed. The internals of each module is checked against the list of unsatisfled externals untll all the necessary modules are loaded. Ail modules loaded during this pass are saved on the scratch flie (SC).

Pass 2 - During the second pass, all references to external names are satisfled from the symbol table. The modules on file SC are read during this pass, and a self-contalned load module is written on the BInary Output (BO) flle.

M4E has several directlves and options that control the link edit process. Thls document will describe only the common directives and options.

\section{Directives}

- The only directlve that will be described is the mandatory "EDIT" directlve. there are several other M4E directives that may be found in the reference manual. The "WEO" and "EXIT" directives are the same Identical to the ones used in the other System Processors.

EDIT - This directlve is required to perform link editing of the object miodules.

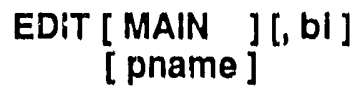

Where: "pname" is a program name to link edit

"bl" Is a logical flle name

If "MAIN" is entered, the flrst object module read from the "bl" flle will be llnk edlted

If no parameters are entered, then MAIN and the Binary Input ( BI) file are the defaults

Examples:

EDIT myprog BI
EDI abc,SI
EDIT
EDIT MAIN,SI
EDI


The common M4E optlons are:

LO "If option LO is on, the MAE directives will be written to the LO flle. The default is LO.

NOLO - If option NOLO is on, the M4E directives will no be written to LO.

MAP - If Optlon MAP is on, a Map llsting of the symbol table will be written to the LO flle. The default is MAP.

NOMAP - If Optlon NOMAP is on, a Map llsting will not be written.

The M4E LInk Editor is executed as follows:

\$EXE MAE,,[ OPT1 ], [ OPT2 ],[ OPTn ] Where: OPT1,OPT2,OPTn are the selected optlons EDIT

WEO BO

EXI

The flle usage is described as follows:

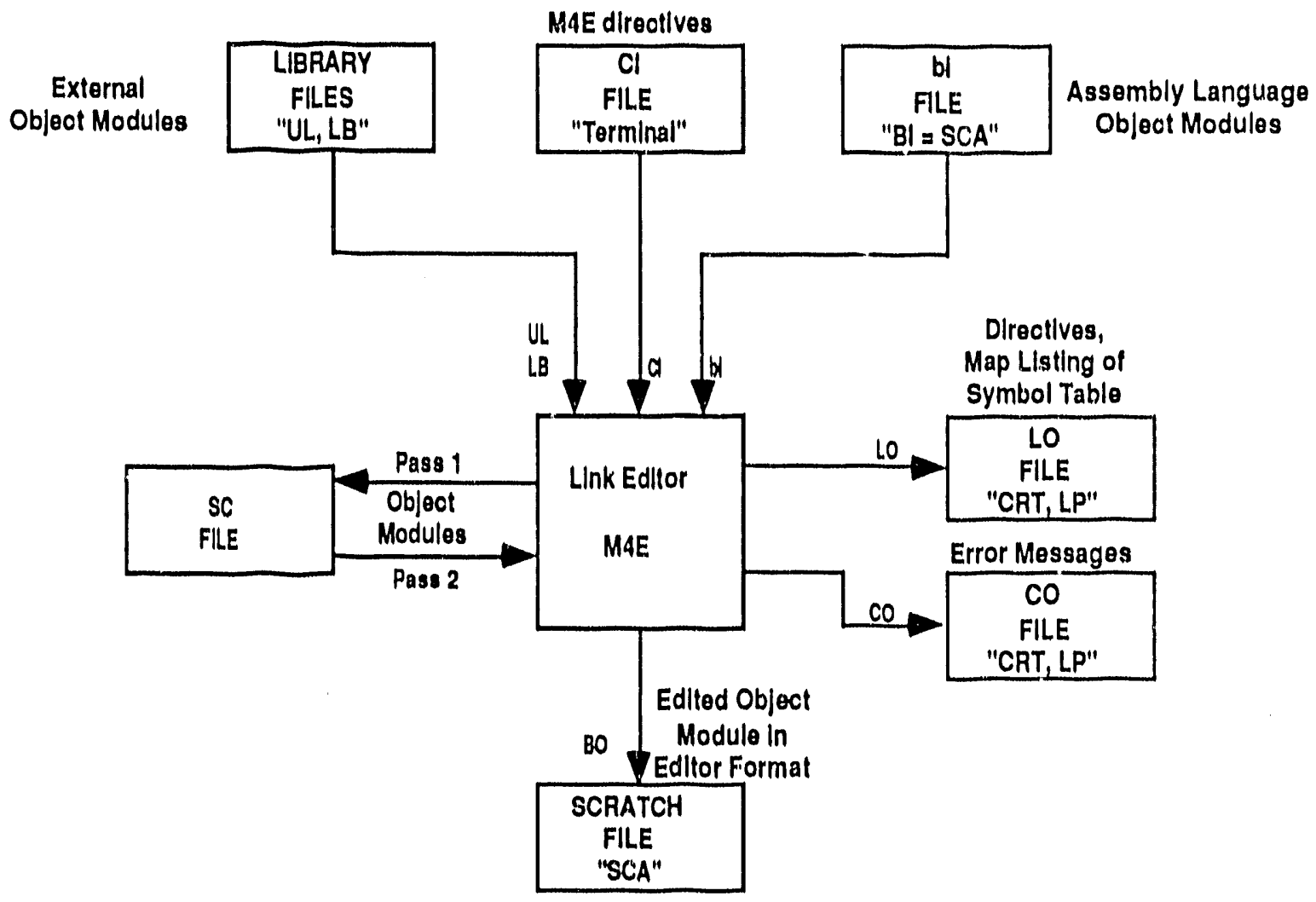


The LInk Editor M4E has many more directives than the ones described above. For a more detalled description of the MAE directives, refer to the following mariual:

Programmer's Reference Manual MAX IV

System Processors

Link Editor

\section{Cataloger}

The Task Overlay Cataloger ( TOC ) catalogs program object modules as execuliable object load modules on a load module flle. TOC reads the program object module from the Binary input (BI) flle. The program object module may have been generated by the Link Editor (M4E), or read as another load module. TOC has many directlves used in cataloging a program that define the environment in which the loaded program operates. TOC transparently allocates default values to a user not requiring any speclal resources. However, other users who requile speciflc characteristics for a partlcular program, uses the TOC directlves to specify default values explicitly. This document will describe only the very basic TOC directlves. It is suggested that the user read the reference manual for a detalled descriptlon of the TOC directives. 


\begin{tabular}{|c|c|c|}
\hline DIRECTIVE & DESCRIPTION & EXAMPLES \\
\hline TASK [name] [prl] [llm] & $\begin{array}{l}\text { The TASK directlve declares that the next } \\
\text { program to be cataloged is a task. The optlonal } \\
\text { "name" parameter speclfies the } 1 \text { to } 6 \text { character } \\
\text { task name. Default is the actual program name. } \\
\text { The optlonal "prl" parameter sets the tasks } \\
\text { executlon prlorlty level }(0-255) \text {. A defau!t is } \\
\text { speclfled by the task that schedules or activates } \\
\text { the task. The optlonal parameter "llm" is the task } \\
\text { influence limlt }(0-255) \text {, this task has over other } \\
\text { tasks. The default is priority level. }\end{array}$ & $\begin{array}{l}\text { TASK PROG1 } 10010 \\
\text { TAS, }, 10010 \\
\text { TAS }\end{array}$ \\
\hline QVER [name] & $\begin{array}{l}\text { The OVERLAY directive declares that the next } \\
\text { program tc be cataloged is an overlay. The } \\
\text { optlonal parameter "name" is the same as for } \\
\text { the TASK directlve. }\end{array}$ & $\begin{array}{l}\text { OVER PROG1 } \\
\text { OVE }\end{array}$ \\
\hline FILE fllename & $\begin{array}{l}\text { The FILE dlrectlve speclfles the load-module } \\
\text { logical flle "fllename" that will be used for } \\
\text { subsequent directlves. }\end{array}$ & $\begin{array}{l}\text { FILETM } \\
\text { FIL YY }\end{array}$ \\
\hline CATALOG & $\begin{array}{l}\text { The CAT directlve reads an object program from } \\
\text { the BI flle and catalogs it as a task or an overlay } \\
\text { on the selected load module flle, using all the } \\
\text { accumulated or default resource Informatlon } \\
\text { prevlously selected. }\end{array}$ & CAT \\
\hline $\begin{array}{r}\text { SoU name [file] } \\
\text { [INIT] }\end{array}$ & $\begin{array}{l}\text { The SOURCE dilrective generates a llst of the } \\
\text { resources to the LO flle for the program "name". } \\
\text { It optlonally coples the source of the resources } \\
\text { to a specifled tile "flle", or initiallizes TOC's } \\
\text { internal tables with the resources of the } \\
\text { speclfled task or overlay. }\end{array}$ & $\begin{array}{l}\text { SOUPROG } \\
\text { SOU PROG, INIT } \\
\text { SOU PROG SO }\end{array}$ \\
\hline LIST [fllename] [dir] & $\begin{array}{l}\text { The LIST directlive generates a report on the LO } \\
\text { flle of all programs in the current load-module } \\
\text { flle's directory. Opllonal parameter "filename" } \\
\text { specifles the load-module flle name. If thls } \\
\text { parameter is not specifled, then TOC will llst the } \\
\text { load-module flle speclfled by the last FILE } \\
\text { directlve. Optlonal parametei "dir" speclfles that } \\
\text { only tho directory be IIsted with no valldity } \\
\text { checking. If this parameter is nct specifled, then } \\
\text { TOC verifles the integrity of all the load-modules } \\
\text { in the directory. }\end{array}$ & $\begin{array}{l}\text { LIS } \\
\text { LIS YY } \\
\text { LIS TM DIR }\end{array}$ \\
\hline EXIT & $\begin{array}{l}\text { The EXIT directlve exits TOC and returns the } \\
\text { user to Job Control. }\end{array}$ & EXI \\
\hline
\end{tabular}

The Task/Overlay Cataloger ( TOC ) Is executed as follows:

\author{
SEXE TOC \\ FIL YY \\ OVER program \\ CAT \\ EXI
}


TOC's file usage is described as follows:

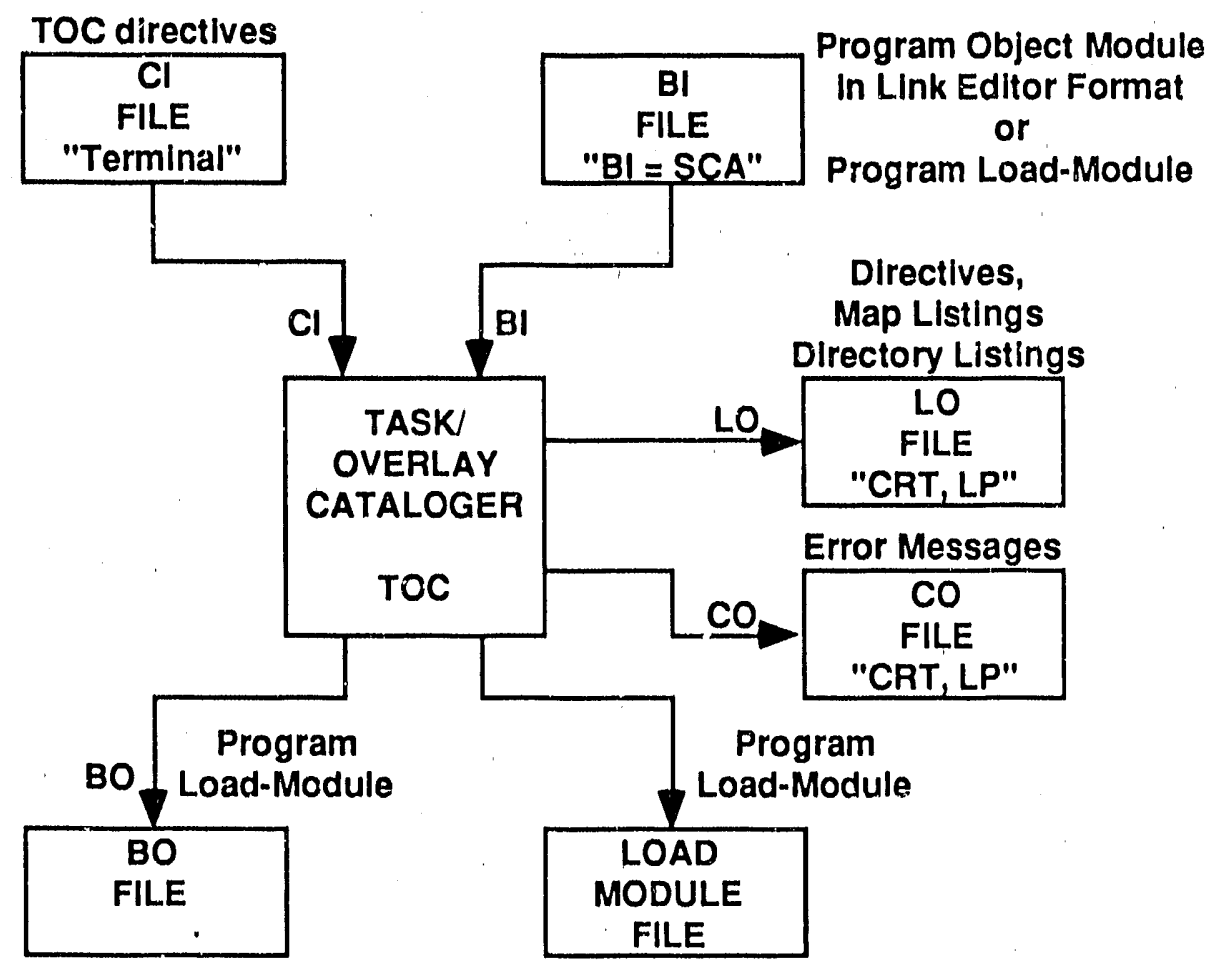

TOC has many more directlves tinan the ones described above. For a more detalled description of the TOC directives, refer to the following manual:

Programm ：Reference Manual MAX IV

Task/Overlay Cataloger 


\section{Multluser System}

The new Neutral Beam System software has a multiuser system to faciliate multibatch Interactlve processing on the Neutral Beam Systems. Each user must sign on to the system with a user password, which sets up the users operating environment. When the system is first booted up, the system sign on message will be displayed to all of the connected terminals. The sign on message will be displatyyed unfli, a user signs on to the system, or the screen saver blanks the screen. The procedure to sign on the system is as follows:

- The user accesses the system, by a directly connected ferminal, or by a terminal connected through the MICOM. Thls Is the same as any of the other systems.

- The System Sign On message may or may not be displayed. The message will not be displayed if, signing on through a MICOM line that was not connected, or the screen saver has cleared the CRT. Whether the message is displayed or not, entering your password will sign you on to the system. Entering anything other than a legal password will result in, the system output an "INVALID PASSWORD" message, and the "System Sign On" message will be displayed.

Presently, there are specific user passwords as well as some general passwords. The system does not allow more than one user to sign on to the same area. The user signs off the system by typing the Job Control commands, "BYE" or "LO", which will cause the user to exit the system, and display the sign on message.

NOTE: Alway; sign off the system by typing "BYE" or "LO" when you are finished using the system. If using a terminal connected through the MICOM. enter "Break" after signing off,

Fallure to sign off the system will, allow an unauthorized user to use your area, prevent other users from signing on to the system from the MICOM. 


\section{Job fontrol Procedures}

There are several Job Control procedures on the system to facilitate using the Systems Processors. There are general procedures for doing source editing, compiling, assembling, link editing, etc. There are also specific procedures for, complilng, assembling, link editing, and cataloging specific programs. These procedures are in the format of "P.progname". At the present time, only the "SEDIT" procedure will be descrlbed as we are in the process of redefining the other. They will be included in this document when they have been defined and implemented.

SEDIT - SEDIT is a procedure that automates the use of the Source Editor (SED ). It may be used to, create, modify, vlew, any program on any USL file.

SEDIT [name] [USL file]

[NEW]
The optlonal parameter "name" specifles the name of the program to edit.

If "NEW" Is entered then it is assumed that a new module is belng created. If the "name" parameter is null, SED performs a random recovery from the work (WRK) flle.

The optlonal parameter "USL file" specifles the name of the USL file. If this parameter is not entered, the USL file default assignment is used.

\section{SEDIT Macros:}

X - DIsplays 20 lines in OPT ONE format from the current line pointer and positions the line pointer forward 20 lines.

$z$ - Positlons the line pointer backward 20 lines and displays 20 lines in OPT ONE format from the new current line pointer.

XX - Same as X except 10 lines are displayed in OPT TWO format.

ZZ - Same as $Z$ except 10 lines are displayed in OPT TWO format.

S - Positions the line pointer backward 10 lines, displays 20 lines from the new current line pointer, repositions the line pointer forward 20 lines.

Note: All of the above macros set OPT TWO after they are executed.

L - Display the last line of the program.

PE - Removes program name used in the SEDIT "name" parameter from the USL file directory, and catalogs the WRK file on the USL flle with the same name. Exits from SED.

PSE - Same as PE except It creates a backup of the program name with a colon in front of the name (l.e. :name). Exits from SED.

SV - Same as PE except it does not exit from SED. The current i!ne pointer stays where It was prior to executing the SV macro. This allows you to save your new progra il while you are working on it.

CAT - This is the SED directlve CAT for cataloging a program on the USL flle. It must be used when the SEDIT parameter "name" Is "NEW" (create new program). I.E. CAT "name".

You may use all of the SED directives while in SEDIT.

\section{Acknowledgements}

This work was sponsored by the U.S. Department of Energy under Contract NO. DE-AC03-89ER51114. 

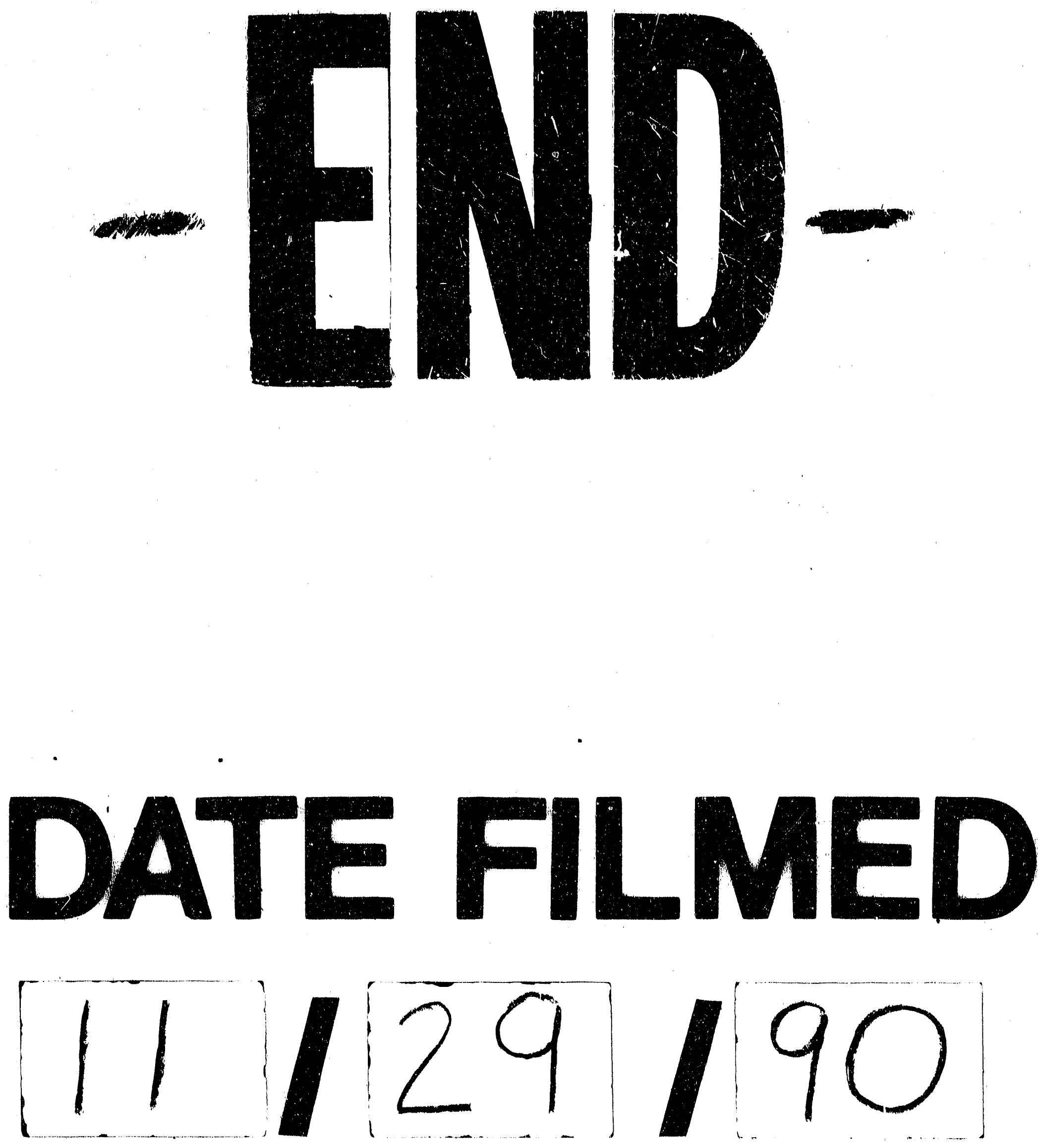


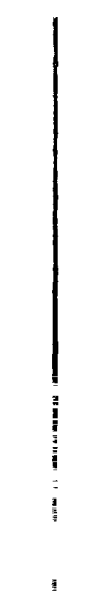

